\title{
Packaging Solution Optimization of Automotive Parts and Its Ocean Shipping Test
}

\author{
C.W. Chen \\ Colleague of Food Science and Technology \\ Shanghai Ocean University \\ China \\ J. Xie \\ Colleague of Food Science and Technology \\ Shanghai Ocean University \\ China \\ Shanghai Engineering Research Center of Aquatic-Product \\ Processing \& Preservation \\ China \\ Corresponding author
}

\author{
F.X. Yang \\ Colleague of Food Science and Technology \\ Shanghai Ocean University \\ China \\ Shanghai Engineering Research Center of Aquatic-Product \\ Processing \& Preservation \\ China \\ D.D. Yang \\ Borg Warner Automotive Components (Ningbo) Co., Ltd, \\ China
}

\begin{abstract}
To obtain optimized packaging solution of the exported automotive parts to avoid rust during logistics. The old packaging solution was studied. Five improved Volatile Corrosion Inhibitor (VCI) anti-rust packaging solution was designed and tested by real ocean shipping. Optimized anti-rust packaging solutions gained by analyzing and comparing their anti-rust packaging results and packaging costs via ocean shipping test. The excessive packaging was avoided, the packaging cost was reduced and the packing work efficiency was increased. The method and results were valuable reference for automotive parts anti-rust packaging design and engineering application.
\end{abstract}

Keywords-packaging solution optimization; automotive parts; VCI anti-rust packaging; ocean shipping test

\section{INTRODUCTION}

The production characteristics of automotive industry are that the parts are manufactured dispersedly and centralized assembled into vehicle. Most automotive parts are metal products, so it is very important to avoid rust during logistics. Due to rust, the automotive parts' precision, sensitivity and reliability reduce, which affects their use values, even to be declared worthless, and the economic loss of export parts is bigger because of return of goods, repair and compensation [1] However, the rust can be reduced or avoid through reasonable anti-rust packaging.

Volatile Corrosion Inhibitor (VCI) is a volatile corrosion inhibitor that is composed with special ingredient [2-4]. VCI anti-rust packaging technology is the technology that using the VCI material gaseous phase to protect the metal products from corrosion [5-8].The major anti-rust packaging type of automotive parts is VCI anti-rust technology, which doesn't need the processes of getting rid of the oil and washing after opening the packaging, and can be put onto the production line directly. It improves the production efficiency greatly.
Compared with the rust preventing oil conventional anti-rust technology, the VCI anti-rust technology has more superiority [9-11], but if the inside anti-rust packaging structures are different, there will be great difference of the anti-rust packaging effect and packaging cost. Whether the VCI antirust packaging structures and quantity of VCI material are reasonable or not, it needs actual transportation experiment or climate simulation experiment to validate.

In this study, the old packaging solution of one export part from an automotive parts company was studied. The improved VCI anti-rust packaging solution was designed and tested by ocean shipping. Optimized anti-rust packaging solutions gained by analyzing and comparing their anti-rust packaging results and packaging costs via ocean shipping test. The excessive packaging was avoided, the packaging cost was reduced and the packing work efficiency was increased. This method and results were valuable reference for automotive parts anti-rust packaging design and engineering application.

\section{CHARACTERISTICS OF THE PART AND ANTI-RUST PACKAGING REQUIREMENTS}

The outside housing of the part is iron casting, which is easy to be rust. The shape of part is irregular with outside dimension $245^{*} 130 * 150 \mathrm{~mm}$, and the weight is about $4.5 \mathrm{~kg}$. The part is manufactured in an automotive company in Ningbo of China and is exported to the plant of GM automotive engine in USA. The type of transportation is ocean shipping, which easily cause the part rust. So the anti-rust packaging is very important except the packaging should protect the parts from impact and vibration. The anti-rust shelf life required by customer must reach 6 months from ex-factory date. The rust level of part defined by customer is presented in Table 1 and this part should meet third level. 
TABLE I. URUST LEVEL OF PART.

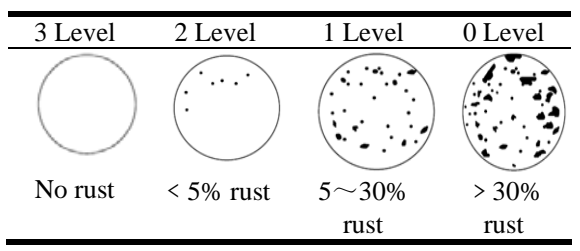

\section{ANTI-RUST PACKAGING METHOD ANALYSIS AND IMPROVEMENT}

\section{A. Old Packaging Solution}

The old packaging solution was expendable packaging and the detail information was as follow:(1) Packaging type: wooden pallet + outside carton + big plastic bag + cardboard divider/clapboard + individual VCI-bag, Fig. 1 is diagram of packaging solution;(2) Anti-rust type: every part sealed with individual VCI-bag, big plastic bag sealed inside. There was no rust issue for this anti-rust type;(3)Outside dimension: 1140*980*740mm;(4) Packaging quantity: 24 parts / layer, 4 layers, total 96 parts;(5) Gross weight: 600kg/Pallet.

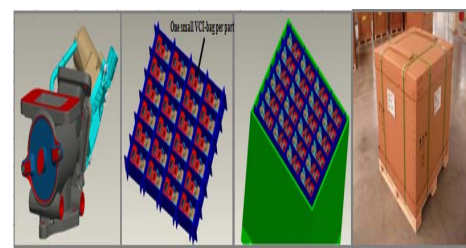

FIGURE I. PART'S OLD PACKAGING SOLUTION.

There were some problems of the old packaging solution after investigation, as follow: (1) Low packing efficiency. When packing, every part needed to be put into the individual VCI-bag and sealed with adhesive tape, then was put into the carton. The average time of packing one part was about 18 seconds based on the statistic and analysis for packing time of one pallet of three different work shifts.(2) Low efficiency of disassembling packaging. When using the parts on customer production line, it needed to get rid of the adhesive tape first before the part was taken out from the individual VCI-bag. The average time of disassembling one part was about 16 seconds based on the statistic and analysis.(3) High anti-rust packaging cost. anti-rust packaging cost was about $30 \%$ of total packaging cost.

\section{B. Improved Packaging Solution}

It should consider to change "one part with one VCI-bag" packaging type firstly to improve the packing efficiency and reducing the packaging cost based on above analysis. But the corrugated cardboard absorbed moisture easily [12], and the part would be rust if it was contacted with the corrugated cardboard for long time. So the cardboard divider/clapboard was advised change to the plastic material if anti-rust packaging type was considered to change. The plastic corrugated board is a board that has merits as follow: light, good mechanical property, waterproof, damp-proof, heat insulation etc [13]. And different weight/thickness material can be chosen according to different requirements of strength. So it was reasonable and feasible to change the cardboard divider/clapboard to plastic corrugated board.
Five improved packaging solutions were designed and taken to do the ocean shipping test. Detail improved packaging solutions explanation and diagram was presented in Table 2 and Fig. 2. The packaging structures of five improved packaging solutions were almost the same with the old packaging, and the main differences of them were inner packaging material and anti-rust packaging type.

\section{TABLE II . COMPARISON OF IMPROVED ANTI-RUST PACKAGING} SOLUTION.

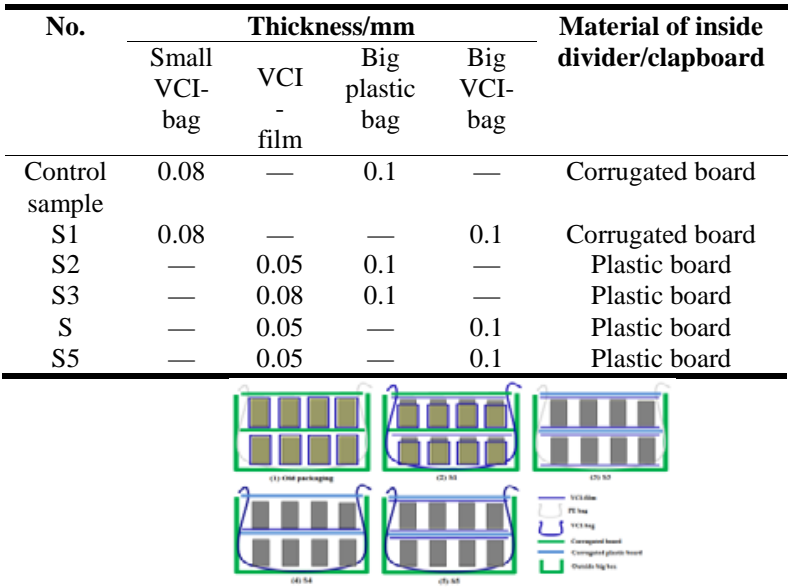

FIGURE II . DIAGRAM OF DIFFERENT IMPROVED ANTI-RUST PACKAGING SOLUTION.

\section{Ocean Shipping Testing}

(1) Samples: there were two boxes of five improved packaging solutions for testing respective, which were made by Tri-wall in Ningbo of China. Every part was packed after it was inspected as acceptable part for these ten boxes samples according to the quality standard. And the packing work was carried out according to the packaging work instruction strictly and the packing time of each packaging solution was recorded.

(2) Transportation route: the parts were shipped to Shanghai dock by road, and then were shipped by ocean to Los Angeles dock in USA, at last were shipped to the customer plant by road.

(3) Testing time: from 5/16/2013 to 7/15/2013, total 45 days, the ocean shipping is 33 days. The parts were produced and packed in 5/16/2013 and sent out in 5/21/2013 after stored at Ningbo plant warehouse. They were arrived at customer plant in 6/28/2013 and were inspected after stored for 6 days in warehouse.

\section{RESULTS AND DISCUSSION}

The ocean shipping test rust results of six different packaging solutions are presented in Table 3.It shows that:(1) Rust of S1 was severest, S2 was in middle, and there was no rust of S3, S4 and S5. Because the inside packaging material is cardboard, which absorbs moisture easily and lead to raise humidity in the carton. Together with big range of temperature on the sea, they cause the parts rust.(2) Comparing S2 with S3, the only difference was the thickness of VCI-film, and S3 was thicker than S2. The concentration of corrosion inhibitor is proportional to the thickness. The results proved that the 
concentration of corrosion inhibitor of S2 was not enough or in a critical state, which cause the parts rust slightly.(3) Comparing S4 with S5, there was one more VCI-film at the top of each layer, but they both met the quality requirement.

In addition, the average time of packing one part of six solutions is also presented in Table 3. The result was: OS > S1 $>\mathrm{S} 2=\mathrm{S} 3=\mathrm{S} 4=\mathrm{S} 5$. The packing efficiency was improved five times after changing from the individual VCI-bag to spread VCI-film.

\section{TABLE III. OCEAN SHIPPING TEST RUST RESULTS OF DIFFERENT PACKAGING SOLUTION.}

\begin{tabular}{cccc}
\hline No. & $\begin{array}{c}\text { Quantity } \\
\text { of rusty } \\
\text { parts }\end{array}$ & Rust description & $\begin{array}{c}\text { Average } \\
\text { time of } \\
\text { packing one } \\
\text { part /S }\end{array}$ \\
\hline $\begin{array}{c}\text { Control } \\
\text { sample } \\
\text { S1 }\end{array}$ & 0 & No rust & 18 \\
& 13 & $\begin{array}{c}\text { 3 } \sim \text { 4 rusty parts } \\
\text { each layer, 1 rust } \\
\text { level }\end{array}$ & 10 \\
S2 & 3 & $\begin{array}{c}\text { rusty parts is on } \\
\text { the top layer, } 2 \\
\text { rust level } \\
\text { No rust }\end{array}$ & 3 \\
S3 & & No rust & 3 \\
S4 & 0 & No rust & 3 \\
S5 & 0 & 0 &
\end{tabular}

Remark: Time of packing one part is the time that the part packed into the box.

The packaging cost of six packaging solution is shown in Table 4. Combined the testing results and cost economical efficiency, S4 was the best solution. Compared with old solution, the cost of S4 reduced 12\%. S4 packaging solution was implemented from $8 / 13 / 2013$, and there was no rust issue till now.

\section{TABLE IV. COST COMPARISON OF IMPROVED ANTI-RUST} PACKAGING SOLUTION.

\begin{tabular}{cccc}
\hline No. & $\begin{array}{c}\text { Anti-rust } \\
\text { packaging } \\
\text { cost } \\
\text { (RMB/par } \\
\text { t) }\end{array}$ & $\begin{array}{c}\text { Packaging } \\
\text { cost } \\
\text { (RMB/p } \\
\text { art) }\end{array}$ & $\begin{array}{c}\text { Reduce } \\
\text { percent } \\
\text { age/\% }\end{array}$ \\
\hline Control & 1.99 & 6.46 & - \\
sample & & & \\
S1 & 1.19 & 5.80 & $10 \%$ \\
S2 & 0.46 & 5.65 & $13 \%$ \\
S3 & 0.63 & 5.82 & $10 \%$ \\
S4 & 0.50 & 5.69 & $12 \%$ \\
S5 & 0.64 & 5.83 & $10 \%$ \\
\hline
\end{tabular}

\section{V.CONCLUSIONS}

Optimized anti-rust packaging solution of exported automotive part was obtained by analyzing and comparing their anti-rust packaging results and packaging costs. The packaging cost was reduced and packing work efficiency was increased for the company.

This method and results provided valuable reference for automotive parts anti-rust packaging design and engineering application: (1) If the inside packaging is cardboard or other hygroscopic material, there is rust risk during logistics, especially ocean shipping, even though there is VCI-film protecting and not in direct contact with the inside packaging material.(2) Be prior to adopt the solution with spread VCIfilm and plastic material as inside packaging mode.(3) Even though the VCI packaging type is same, the anti-rust effect will be different if the amount of VCI-film or the concentration of corrosion inhibitor is different.(4) On the precondition of meeting anti-rust requirement, more economical solution should be priority to avoid excessive packaging based on the packaging cost analysis.

\section{ACKNOWLEDGMENTS}

This study has been financed by Shanghai Young Teachers Development Program in Colleges and Universities (B-540913-0014), the project Shanghai Science and Technology Committee Engineering Research Center Construction: Shanghai Engineering Research Center of Aquatic-Product Processing \& Preservation (11DZ2280300), and was support by Borg Warner Automotive Components(Ningbo) Co., Ltd.

\section{REFERENCE}

[1] Hui-yun Wang, Mechanism And Application of Rustproof Packaging. Packaging Engineering, 17(6), pp. 11-15, 1996.

[2] E. Vuorinen, W. Skinner, Amine carboxylates as vapour phase corrosion inhibitors, Br. Corros. J. 37 (2002) 159-160.

[3] D. Zang, Z. An, Q. Pan, L. Gao, G. Zhou, Volatile corrosion inhibitor film formation on carbon steel surface and its inhibition effect on the atmospheric corrosion of carbon steel, Appl. Surf. Sci. 253 (2006) 13431348.

[4] W. Skinner, A new method for quantitative evaluation of volatile corrosion inhibitors, Corr. Sci. 35 (1993) 1491-1494

[5] S.B. Valdez, R.K. Zlatev, W.M. Schorr, G.N. Rosas, Ts. Dobrev, M. Monev, I.Krastev, Rapid method for corrosion protection determination of VCI films,Anti-Corr. Methods Mater. 53 (6),pp. 362-366, 2006.

[6] D.M. Bastidas, E. Cano, E.M. Mora, Volatile corrosion inhibitors: a review, Anti-Corr. Methods Mater. 52 (2), pp. 71-77, 2005.

[7] U. Rammelt, S. Koehler, G. Reinhard, Use of vapour phase corrosion inhibitors in packages for protecting mild steel against corrosion. Corrosion Science, 51, pp. 921-925, 2009

[8] Yan-qiu Tang, Oil-free Rustproof Packaging for Automotive Components. Automobile Technology\&Material,8(1), pp. 41-42, 2003.

[9] Zhi-guang Li, Hongjun Huang, Hongjing Wang, Min Zhang, Anticorrosion effect and preliminary filming time of a volatile corrosion inhibitor paint. Corrosion \& Protection, 27(3), pp. 133-135, 2006.

[10] Yanxue Xue, Ming Xiang, Research on Method for Motor Transport Package.Packaging Engineering,22 (5), pp. 47-51, 2001.

[11] Wen-zhaoLi, Chun-lei Tian, Liangchun Li, Study of ammunition packaging based on vapor phase inhibitor technology.Packaging Engineering,27(1), pp. 112-113, 2006.

[12] Guang-jun Hua, Ding-ti Luo, Luo-Mei Wu, The Simulation Analysis of Corrugated Board Strength Based on Buckling Criteria. Packaging Journal, 2(1), pp. 18-20, 2010

[13] Xianggang Li, Yuejun, Liu, The present situation and the trend of the study of the plastic corrugated sheet.Journal of Zhuzhou Insitute of Technology,20(6), pp. 4-7, 2006 